\title{
Value seeking and prediction-decision inconsistency: Why don't people take what they predict they'll like the most?
}

\author{
CHRISTOPHER K. HSEE \\ University of Chicago, Chicago, Illinois
}

\begin{abstract}
In this research, it is proposed that, when making a choice between consumption goods, people do not just think about which option will deliver the highest consumption utility but also think about which choice is most consistent with rationales-beliefs about how they should make decisions. The present article examines a specific rationale, value seeking. The value-seeking rationale refers to the belief that one should choose the option in a choice set that has the highest monetary value. Studies 1 and 2 show that value seeking could lead to a prediction-decision inconsistency, predicting a high consumption utility from one option but choosing another option. Study 3 shows that the predictiondecision inconsistency could be created even by "illusory" (as opposed to truly monetary) values and that the inconsistency could be turned on or off through empirical manipulation.
\end{abstract}

A fundamental question in decision research is whether people would forego an option that has a higher consumption utility to choose one with a lower consumption utility, holding cost constant. The consumption utility of an option is broadly defined here as the benefit the option delivers. ${ }^{1}$ For example, the consumption utility of an ice cream cone is the enjoyment the consumer derives when he/she eats it.

Casual observations suggest that decision makers often fail to choose the option in a choice set that has the highest consumption utility. For example, a customer at an ice cream parlor may decide to order a particular type of ice cream from the menu but does not enjoy it when he/she eats it.

There are at least two possible reasons why people may fail to choose the highest consumption utility option. First, they do not accurately predict which option will deliver the highest consumption utility (e.g., Kahneman \& Snell, 1990, 1992). They choose an option with the belief that it has the highest consumption utility, but, when they consume it, they realize it does not. Second, people do not always use their predictions of consumption utility to guide their decisions (Kahneman, 1994). The former reason can be referred to as prediction-consumption inconsistency, and the latter can be referred to as predictiondecision inconsistency.

In the existing literature, one can find abundant work on prediction-consumption inconsistency. For example, people cannot accurately predict adaptation effects or taste

The author thanks Donna Dreier, Danny Kahneman, Josh Klayman, Cade Massey, Dick Thaler, and John Wright for their comments on earlier versions of this paper. Correspondence should be addressed to $\mathrm{C}$. $\mathrm{K}$. Hsee, Graduate School of Business, University of Chicago, $1101 \mathrm{E}$. 58th St., Chicago, IL 60637 (e-mail: christopher.hsee@gsb.uchicago.edu). changes (e.g., Kahneman \& Snell, 1990, 1992; Loewenstein \& Frederick, 1997; Loewenstein \& Schkade, 1998; March, 1978; Schkade \& Kahneman, 1998); people in one arousal state do not know what they would do or like in a different arousal state (e.g., Loewenstein, 1996; see also Ainslie, 1975); prediction and decision are often made in a joint evaluation mode, and consumption takes place in a single evaluation mode (e.g., Hsee, 1996b, in press; Hsee, Loewenstein, Blount, \& Bazerman, 1999).

In contrast, little is known about prediction-decision inconsistency. This inconsistency will be the focus of the present paper. Common sense tells us that, when given a choice between two options (assume that these options are free or require us to pay the same amount of money), we should think about the consumption utility of the options and choose the one that we predict to have the higher consumption utility. In reality, people do not always do so.

Several existing lines of research have inspired the present work. Social psychologists have observed that people seek justifications and accountability for their behaviors (e.g., Hsee, 1995, 1996a; Kunda, 1990; Tetlock \& Boettger, 1989; Tetlock \& Kim, 1987). More specific to decision making, Shafir, Simonson, and Tverksy (1993) proposed that, in making a choice, people do not alway s choose the best option but choose the option that is easiest to justify. Prelec and Herrnstein (1991) argued that people often do not perform cost-benefit analyses to solve a decision problem; instead, they resort to personal or moral principles and choose the option that is most consistent with these principles. Most influential to the present research is Thaler's (1985, in press) transaction utility theory. The theory posits that a consumer's decision to purchase a product depends not merely on how much the consumer needs the product (which is called the $a c$ quisition utility) but also on whether the consumer per- 
ceives the purchase as a good bargain or a "rip-off" (which is called the transaction utility).

Built on these previous lines of research, the general thesis of this article is that, when making a decision, people do not just think about whether or not the consequence of their decision is good; they are also concerned with whether or not their decision per se is good. People have a set of standards, or rationales, for what constitutes a good decision. When making a decision, people strive to choose the option most consistent with these rationales.

This article focuses on one particular rationale: value seeking. It refers to the belief that in decision making, one should choose the option in the choice set that has the highest economic or monetary value. For example, suppose that a person is given a choice of two buffets - one normally costing $\$ 15$ and the other normally costing $\$ 30$ and that both buffets are now free. The value-seeking rationale would compel the individual to take the $\$ 30$ buffet. (See Hsee, 1999, for a more comprehensive treatment of the rationale-seeking topic, which includes other rationales).

The value-seeking rationale would be a perfect rule to follow if, in any given pair of options, the higher value option were always the one that has the higher consumption utility. But this is not always true. For example, the type of cuisine in the $\$ 15$ buffet may be different from that in the $\$ 30$ buffet, and some people may enjoy the $\$ 15$ buffet more. In such circumstances, following the valueseeking rationale may lead the decision maker to forego the option with the highest consumption utility.

It should be noted that if one chooses a lower consumption utility option simply because he/she does not know (i.e., cannot predict) which option has the highest consumption utility, then it is not interesting. The thesis here is that, even in situations in which consumers do have additional information and are able to make the prediction, they may still follow the value-seeking rationale in decision making and choose that option. Thus, the present research was not just designed to show that people favor high-value options or good bargains but to demonstrate that their decisions deviate from their predictions about consumption utility. Specifically, this research shows that when giving a direct choice between a lowvalue option and a high-value option, consumers would choose the high-value option even if they predict a higher consumption utility from the low-value option.

To the best of my knowledge, there has been no empirical study that directly explores this type of inconsistency. There are, however, two related studies. One is reported in Simonson's (1990) article on variety seeking. Participants were asked either to make candy selections for future consumption occasions or to predict their preferences during those occasions. The result revealed a prediction-decision inconsistency: Those in the selection (decision) condition sought more variety than those in the prediction condition. Although the motivation underlying variety seeking may not be related to value seeking, the finding of that study corroborates the thesis here that people do not always use their predictions to guide their decisions.

Another study in the existing literature that documents a prediction-decision inconsistency is reported by Tversky and Griffin (1991). Participants in that study evaluated hypothetical job offers from two companies. One offered them $\$ 33,000$ a year and their colleagues only $\$ 30,000$ a year. The other company offered them $\$ 35,000$ a year and their colleagues $\$ 38,000$ a year. Most respondents predicted greater happiness by working at the former job, but they decided to take the job with more salary (the latter job). In a sense, one's happiness at a job can be construed as the "consumption utility" of that job. In that sense, this study is a telling demonstration of a prediction-decision inconsistency. The finding supports the value-seeking notion, suggesting that people would choose to work at higher paying jobs even though people predict themselves to be happier at lower paying jobs. Tversky and Griffin explained their result in terms of justification, assuming that it is more justifiable to choose a higher paying job than a lower paying job. Their explanation is compatible with the proposition here that people seek rationales in decision making.

There is, however, another potential explanation for Tversky and Griffin's (1991) intriguing finding. Participants may have focused on different time horizons when predicting their feelings than when making the decision. When predicting their feelings, they were only asked to predict their experiences at the job, but when they made the decision, participants may have considered the consumption utility of the money that they could enjoy outside of their job or after their retirement.

It should be noted here that the kind of confounding problem mentioned above is usually difficult, if not impossible, to eliminate in research on prediction-decision inconsistency. If participants' decisions differed from their predictions, it is always possible that the researcher did not ask the "right" prediction question. This problem may have existed in the studies in the present research, as well. However, I believe that, although each individual study may be open to multiple explanations, the only explanation that could tie all of these studies together is the rationale-seeking notion - in particular, the value-seeking effect.

Below, I report on a set of studies that tested for prediction-decision inconsistency. The first two studies showed that when participants were given a choice between two options (both of which were free), a significant proportion of them chose the option with a higher monetary value, even though, when asked, they thought the other option would render a higher consumption utility. The third study revealed that the prediction-decision inconsistency could be created even by illusory values rather than real monetary values and that the predictiondecision inconsistency effect could be turned on or off through the manipulation of the illusory value attribute. 


\section{STUDY 1}

Chocolate Study

\section{Method}

The options in Study 1 were two chocolates, one more expensive and bigger and the other with a more attractive shape. Respondents (141 students solicited at the dining halls and libraries at two Midwestern universities) were asked to imagine that they had won a lottery drawing at a Christmas party where everybody could pay $\$ 1$ to participate in the drawing. They were given two chocolates to choose from as their prize. ${ }^{2}$ The chocolates were described as follows.

$\begin{array}{lll} & \text { Chocolate A } & \text { Chocolate B } \\ \text { Value } & 50 \text { cents } & \$ 2.00 \\ \text { Net weight } & 0.5 \mathrm{oz} & 2.0 \mathrm{oz} \\ \text { Type } & \text { Milk chocolate from Austria } & \text { Milk chocolate from Austria } \\ \text { Shape } & \text { A lovely heart } & \text { A cockroach that looks ex- } \\ & & \text { tremely real and disgusting }\end{array}$

The participants were asked two questions: one about their prediction and one about their decision. The prediction question was, "Will you feel better when you eat Chocolate A or Chocolate B?" The decision question was, "Will you choose Chocolate A or Chocolate B as your lottery prize?" These questions were given within subjects in order to examine whether the same participants would switch their responses from one question to the next in a systematic direction. The order of the questions was randomized.

\section{Results}

The main finding is presented in the "All Participants" row in Table 1. Sixty-eight percent of the participants opted to take the larger/roach-shaped chocolate, but only $46 \%$ predicted they would feel better eating it. ${ }^{3}$ The difference is significant by McNemar's test of symmetry. It appears that the participants were more concerned with and more influenced by the value-seeking rationale in making a decision than in making a prediction.

The last two rows in the table break down the results depending on whether the participants answered the decision question first or the prediction question first. Both groups of participants exhibited a significant predictiondecision inconsistency.

It is interesting to note that the last two rows of the table reveal an order effect: The prediction-decision discrepancy was somewhat less pronounced for those who answered the prediction question first than for those who answered the decision question first. Although this order effect was not significant in this study, it replicated itself in the other studies as well. It suggests that when asked to make a prediction prior to their decision, some participants aligned their choices with their predictions.

\section{STUDY 2 Map/Journal Study}

Study 2 replicated the prediction-decision inconsistency in a more realistic context.

\section{Method}

The participants were $34 \mathrm{MBA}$ students from a midwestern university enrolled in a managerial decision-making course. Study 2 was embedded in an unrelated in-class exercise for the course.

The students were told that the winner of the exercise would receive a prize and that there were two prizes to choose from: One was an Illinois Road Map priced at $\$ 2.95$, and the other was four recent issues of an academic journal (the Journal of Advertising) priced at $\$ 40$ (the journal contains only professional articles and has a plain cover, like most professional journals). The professor showed the students both prizes, including the inside pages of the journal, and told them about the prizes' respective prices. The students then answered a series of questions printed on a questionnaire. Most of the questions pertained to the unrelated in-class exercise. Two, however, were designed for the present study. One of them asked, "If you win this game, which of the two prizes will you choose to have?" The other question asked, "Of the two prizes you can choose from, which one do you think is more useful to you?" The two questions were printed in random order on different pages and separated by several filler questions about the exercise. Notice that, unlike the prediction questions in Study 1, which were about consumption feelings, the prediction question here asked about usefulness. The reason I asked about usefulness rather than feelings was that maps and journals were primarily tools, and, for tools, I assumed that the word useful was more appropriate to describe their consumption utility.

\section{Results}

The results, summarized in Table 2, again reveal a clear prediction-decision discrepancy. This discrepancy occurred only to the participants who made the choice (decision) first. Of those participants, $63 \%$ chose to have the more expensive journal, but only $27 \%$ thought it was more useful.

\section{STUDY 3 \\ Beatles/Streisand Study}

Study 3 extended Studies 1 and 2 in two major directions. First, the options in Study 3 did not involve any monetary values; instead, it involved only a "pseudo value." A pseudo value is an attribute that gives the consumer the illusion that one option has a higher value than the other but, in actuality, does not affect the product the person eventually consumes. I was curious whether the valueseeking rationale would compel the participants to choose options with only high pseudo values.

Table 1

Percentages of Participants Favoring the More Expensive/Roach-Shaped Chocolate

\begin{tabular}{lccc}
\hline & \multicolumn{2}{c}{ Question } & \\
\cline { 2 - 3 } & Decision & Prediction & Difference $(p)$ \\
\hline All participants & $68 \%$ & $46 \%$ & $<.001$ \\
Participants answering the decision question first & $66 \%$ & $38 \%$ & $<.001$ \\
Participants answering the prediction question first & $70 \%$ & $54 \%$ & $<.01$ \\
\hline
\end{tabular}


Table 2

Percentages of Participants Favoring the Journal

\begin{tabular}{lccc}
\hline & \multicolumn{2}{c}{ Question } & \\
\cline { 2 - 3 } & Decision & Prediction & Difference $(p)$ \\
\hline All participants & $47 \%$ & $30 \%$ & $<.05$ \\
Participants answering the decision question first & $63 \%$ & $27 \%$ & $<.05$ \\
Participants answering the prediction question first & $33 \%$ & $33 \%$ & n.s. \\
\hline
\end{tabular}

There is another key difference between Study 3 and Studies 1 and 2: Studies 1 and 2 merely demonstrated the prediction-decision inconsistency phenomenon, whereas Study 3 showed that the inconsistency can be turned on or off empirically.

\section{Method}

The participants were 117 students from a West Coast university who participated in this study as a course requirement. They were assigned to either the no-point condition or the point condition. Those in the no-point condition were asked to imagine that they were participating in a boring psychology experiment on memory in exchange for a music compact disc (CD). They were told that they could choose to complete either Task X or Task Y, that the two tasks were identical except that Task $X$ would last $50 \mathrm{~min}$ and Task $Y$ would last $60 \mathrm{~min}$, and that the experimenter had no preference which task they chose. The participants were further told that doing Task $X$ would entitle them to a free $C D$ of greatest hits by the Beatles and doing Task $Y$ would entitle them to a free $C D$ of greatest hits by Barbara Streisand. The participants in the point condition received the same instructions as the as described above, with the following exception: They were told that they would receive points for their participation, and that 50 points would entitle them to a $\mathrm{CD}$ of greatest hits by the Beatles and 90 points would entitle them to a $\mathrm{CD}$ of greatest hits by Barbara Streisand. They were further told that if they did Task $X$, they would receive 50 points, and if they did Task $Y$, they would receive 90 points.

Thus, the point condition was identical to the no-point condition except that a pseudo-value attribute (number of points) was introduced between the tasks and the rewards. The design is summarized as follows:

No-Point Condition,

Task X $\rightarrow \quad$ Beatles CD

Task Y $\rightarrow \quad$ Streisand CD

Point Condition

Task $X \rightarrow 50$ points $\rightarrow$ Beatles $C D$

Task Y $\rightarrow 90$ points $\rightarrow$ Streisand CD
In both conditions, the participants were asked to predict which $\mathrm{CD}$ they would more enjoy listening to and which task they would choose. The response was given on a 4-point scale, ranging from 1 (definitely the Beatles $C D$ or definitely Task $X$ ) to 4 (definitely the Streisand $C D$ or definitely Task $Y$ ). The two questions were separated by unrelated fillers, and the order of the questions was counterbalanced.

The prediction for the study was that there would be no predictiondecision inconsistency in the no-point condition and that there would be a significant one in the point condition. This prediction implies a 2 (point versus no-point) $\times 2$ (decision vs. prediction) interaction.

\section{Results}

Table 3 summarizes the results. As expected, in the nopoint condition, there indeed was no prediction-decision inconsistency. This was true regardless of whether the participants answered the decision question first or the prediction question first. Also as expected, in the point condition, a significant prediction-decision inconsistency emerged $(p<.001)$. As in Studies 1 and 2, the predictiondecision inconsistency was more pronounced for the participants who answered the decision question first than for those who made the prediction first.

To examine the interaction between the point manipulation and the prediction decision inconsistency, a 2 (nopoint vs. point) $\times 2$ (prediction vs. decision) analysis of variance was conducted. The result yielded the predicted interaction $[F(1,115)=11.70, p<.001]$.

These results suggest that the introduction of a pseudovalue attribute can lead people to forego a preferred option to choose a less preferred option. Specifically, in the no-point condition, most of the participants liked the Beatles CD more than the Streisand CD, and most also chose the task that would give them the Beatles CD. Thus, there was no prediction-decision inconsistency.

Table 3

The Beatles/Streisand Study Results

\begin{tabular}{|c|c|c|c|}
\hline & \multicolumn{2}{|c|}{ Question } & \multirow[b]{2}{*}{ Difference $(p)$} \\
\hline & Decision & Prediction & \\
\hline \multicolumn{4}{|c|}{ No-Point Condition } \\
\hline All participants & 1.47 & 1.44 & n.s. \\
\hline Participants who answered the decision question first & 1.55 & 1.57 & n.s. \\
\hline Participants who answered the prediction question first & 1.40 & 1.30 & n.s. \\
\hline \multicolumn{4}{|l|}{ Point Condition } \\
\hline All participants & 2.26 & 1.76 & $<.001$ \\
\hline Participants who answered the decision question first & 2.66 & 1.83 & $<.001$ \\
\hline Participants who answered the prediction question first & 1.86 & 1.69 & $<.10$ \\
\hline
\end{tabular}

Note - Responses were given on a 1-4-point scale; larger numbers indicate greater preference for the Task Y/Streisand CD option. 
Table 4

The Beatles/Streisand Study Results With the Decision and Prediction Responses Considered as Between Subjects

\begin{tabular}{|c|c|c|c|}
\hline \multirow[b]{2}{*}{ Condition } & \multicolumn{2}{|c|}{ Question } & \multirow[b]{2}{*}{ Difference $(p)$} \\
\hline & Decision & Prediction & \\
\hline No Point & 1.55 & 1.30 & n.s. \\
\hline Point & 2.66 & 1.69 & $<.01$ \\
\hline
\end{tabular}

Note-Responses were given on a 1-4-point scale; larger numbers indicate greater preference for the Task Y/Streisand CD option.

However, when the points were introduced, more participants decided to take the task that would give them the Streisand CD instead, yet their predicted preference did not change much, thus creating a discrepancy between decision and prediction. In other words, the introduction of the points had a significantly greater influence on decision than on predictions, as is indicated by the significant two-way interaction effect.

The design of Study 3 also allowed for a betweensubject analysis of the decision and prediction responses. Half of the participants answered the decision question first and half answered the prediction question first, and the decision and prediction questions were separated by fillers. Thus, one can examine the first responses given by the two groups of respondents and consider their responses as between subjects. As Table 4 shows, the betweensubjects results are very similar to the within-subjects results.

The findings of Study 3 highlight the role of a "value" attribute in the creation of prediction-decision inconsistency. When the options in the choice set do not involve a value dimension, people's choices are fairly consistent with their predicted consumption experience. When a value dimension is introduced to the choice set-even if it is an illusory one-it steers people's decisions away from their predictions to the option with more value. ${ }^{4}$

\section{DISCUSSION}

In the last few decades, a vast amount of research has been conducted to investigate when and why decision makers fail to predict their future preferences. The present article complements that growing body of literature by showing that, even if decision makers can make accurate predictions, they do not just use predictions to guide their choices. They also follow rationales. The present research focused on the value-seeking rationale and showed that people tend to choose the higher value option even if they predicted or could predict (if asked) that the alternative option would deliver more consumption utility. It seems that people who believe in the value-seeking rationale are reluctant to accept the idea of foregoing the higher value option to settle with a lesser alternative.

It should be noted that the present research was not intended to imply that the value attribute of an option is not important or not predictive of the consumption utility of the option. Often, the value of an option does sig- nal its quality and is a valid cue for people to use in decision making. However, the point here is that, if the value attribute is an index of the consumption utility of the option, then it should already be incorporated into one's prediction. For example, if one buffet costs $\$ 15$ and another costs $\$ 30$, then people should already integrate the price information into their prediction of which buffet is better. Therefore, when making a choice, they should simply base their decision on their prediction. However, what the present research shows is that consumers tend to give the value attribute more weight in decision than in prediction.

Although the present studies did not probe for underlying processes, the results suggest that decision and prediction may involve different cognitive processes. In prediction, people probably engage in some form of mental simulation of the experiences of consuming the different options (Anand-Keller \& McGill, 1994; McGill \& Anand, 1989; Shiv \& Huber, 1999). In making a decision, people follow the value-seeking rationale and choose the higher value option without carefully imagining its future outcome.

Value seeking is probably not only a decision-simplifying heuristic but also a belief about how one ought to make decisions. People will feel good if they choose the highest value option in the available choice set, thereby complying with the value-seeking rationale. People will feel bad if they fail to do so. These feelings are probably the same as what Thaler (1985, in press) refers to as transaction utility in purchase decisions. Transaction utility is a function of the difference between the price the buyer pays for a product and its reference price; it describes the thrill buyers experience for buying a product below its reference price (a bargain) or the pain they feel for paying more than the reference price (a rip-off). Although the transaction utility notion was originally introduced to describe purchase decisions, it is probably a more general concept that can be used to describe how people feel about the merit of their decision, regardless of whether or not it is a purchase decision. People feel positive (or negative) when they think they have made a "good" (or a "stupid") decision.

The prediction-decision inconsistency effect documented in this research is related to, but not the same as, the prominence effect-the finding that the most prominent attribute in a choice set looms larger in a choice task than in a matching task (Tversky, Sattath, \& Slovic, 1988). There are two possible explanations for the prominence effect. One is that the choice task makes it possible for the decision maker to adopt a simple, lexicographic decision rule, whereas the matching task requires the participant to perform more complicated tradeoff analyses. This explanation does not apply to the prediction-decision inconsistency found in the present research, because, in both the decision task and the prediction task, the participants were only asked to make a choice and they could use the simple lexicographic rule in both tasks. Another explanation for the prominence effect is that peo- 
ple are more concerned with justification in choice than in matching, and it is more justifiable to choose the option superior on the most prominent attribute than to choose the alternative option. This explanation is consistent with the present prediction-decision inconsistency finding, which suggests that people are more concerned with the value-seeking rationale in choice (decision) than in prediction.

The present research has a number of noteworthy limitations. First, it is often difficult to know what constitutes the consumption utility of an option. In each study, I made some assumption of what the consumption utility was in the particular context of the study and constructed the prediction question accordingly. It is possible that my assumptions were wrong. For example, in the Chocolate Study (Study 1), I assumed that the consumption utility of a chocolate was one's feeling while eating it. But this assumption may not be correct. Maybe, for example, the participants wanted to use it to amuse their friends rather than to eat it. If that was the case, then the roach-shaped chocolate may have a greater consumption utility (or "amusement utility"). One can think of such alternative explanations for every study, but these explanations are idiosyncratic and cannot be easily applied to other studies. The value-seeking notion, I believe, is the most parsimonious explanation.

Another caveat about the present research concerns the validity of the participants' predictions. As previously mentioned, the present project was concerned only with prediction-decision inconsistency and not with prediction-consumption inconsistency. It is possible that people's predictions are inaccurate. As a result, even though their decision differs from their prediction, the option they end up choosing may still have the highest consumption utility.

A third limitation of this research is its reliance on consumption utility as a benchmark for prediction-decision consistency. At the outset of this research, I assumed that, ideally, decision makers should think about which option would deliver the greatest consumption utility and then choose that option. Whether or not this premise is correct is debatable. One can argue that consumption utility is just one component of the entire experience that decision makers seek to maximize by making a given decision. Another component is their feelings about the decision per se-namely, the "generalized transaction utility" mentioned earlier. If that is the case, then there is nothing wrong when people choose an expensive/roachshaped chocolate that they do not enjoy eating or when people forego a short task and an attractive reward, such as a Beatles CD, to choose a longer task and a less preferred reward. After all, these people have experienced the joy of making the decision the way they think it should be made.

\section{REFERENCES}

AINSLIE, G. (1975). Specious reward: A behavioral theory of impulsiveness and impulse control. Psychological Bulletin, 82, 463-509.
ANAND-Kel.LER, P., \& MCGill, A. (1994). Differences in the relative influence of product attributes under alternative processing conditions: Attribute importance versus attribute ease of imaginability. Journal of Consumer Psychology, 3, 29-49.

HSEE, C. K. (1995). Elastic justification in decision making: How task irrelevant but tempting considerations influence decisions. Organizational Behavior \& Human Decision Process, 62, 330-337.

HSEE, C. K. (1996a). Elastic justification: How unjustifiable factors influence judgments. Organizational Behavior \& Human Decision Processes, 66, 122-129.

HSEE, C. K. (1996b). The evaluability hypothesis: An explanation for preference reversals between joint and separate evaluations of alternatives. Organizational Behavior \& Human Decision Processes, 67, 247-257.

HsEe, C. K. (1999). Rationale-seeking and prediction-decision inconsistency. Unpublished manuscript.

Hsee, C. K. (in press). Attribute evaluability and its implications for joint-separate evaluation reversals and beyond. In D. Kahneman \& A. Tversky (Eds.), Choices, values and frames. Cambridge: Cambridge University Press.

Hsee, C. K., Loewenstein, G., Blount, S., \& Bazerman, M. H (1999). Preference reversals between joint and separate evaluations of options: A review and theoretical analysis. Psychological Bulletin, 125, 576-590.

KaHneman, D. (1994). New challenges to the rationality assumption. Journal of Institutional \& Theoretical Economics, 150, 18-36.

Kahneman, D., \& Snell, J. (1990). Predicting utility. In R. M. Hogarth (Ed.), Insights in decision making (pp. 295-31 1). Chicago: University of Chicago Press.

Kahneman, D., \& Snell, J. (1992). Predicting a changing taste: Do people know what they will like? Journal of Behavioral Decision Making, 5, 187-200.

Kunda, Z. (1990). The case for motivated reasoning. Psychological Bulletin, 108, 480-498.

LOEWENSTEIN, G. (1996). Out of control: Visceral influences on behavior. Organizational Behavior \& Human Decision Processes, 65 , 272-292.

Loewenstein, G., \& Frederick, S. (1997). Predicting reactions to environmental change. In M. Bazerman, D. Messick. A. Tenbrunsel, \& K. Wade-Benzoni (Eds.), Environment, ethics, and behavior (pp. 5272). San Francisco: New Lexington.

Loewenstein, G., \& SchKade, D. A. (1998). Wouldn't it be nice? Predicting future feelings. In E. Diener, N. Schwartz, \& D. Kahneman (Eds.), Foundations of hedonic psychology: Scientific perspectives on enjoyment and suffering (pp. 85-105). New York: Russell Sage Foundation.

MARCH, J. (1978). Bounded rationality, ambiguity, and the engineering of choice. Bell Journal of Economics, 9, 587-608.

MCGiLl, A., \& ANAND, P. (1989). The effect of vivid attributes on the evaluation of alternatives: The role of differential attention and cognitive elaboration. Journal of Consumer Research, 16, 188-196.

Prelec, D., \& Herrnstein, R. (1991). Preferences or principles: Alternative guidelines for choice. In R. J. Zeckhauser (Ed.), Strategy and choice. Cambridge, MA: MIT Press.

Schkade, D. A., \& Kahneman, D. (1998). Does living in California make people happy? A focusing illusion in judgment of life satisfaction. Psychological Science, 9, 340-346.

Shafir, E., SimonSON, I., \& TVERSKy, A. (1993). Reason-based choice. Cognition, 49, $11-36$

SHIv, B., \& HUBER, J. (1999). The impact of anticipating satisfaction on consumer choice. Unpublished manuscript.

Simonson, I. (1990). The effect of purchase quantity and timing on variety-seeking behavior. Journal of Marketing Research, 27, 150-162.

Tetlock, P. E., \& BoeTTGer, R. (1989). Accountability: A social magnifier of the dilution effect. Journal of Personality \& Social Psychology, 57, 388-398.

TETlock, P. E., \& KIM, J. J. (1987). Accountability and judgment processes in the personality prediction task. Journal of Personality \& Social Psychology, 52, 700-709.

Thaler, R. H. (1985). Mental accounting and consumer choice. Marketing Science, 4, 199-214. 
ThALER, R. H. (in press). Mental accounting matters. In D. Kahneman \& A. Tversky (Eds.), Choices, values and frames. Cambridge: Cambridge University Press.

TVERSKY, A., \& GrifFin, D. (1991). Endowment and contrast in judgments of well-being. In F. Strack, M. Argyle, \& N. Schwartz (Eds.), Subjective well-being: An interdisciplinary perspective (Vol. 21, pp. 101-118). Oxford: Pergamon.

Trersky, A., Sattath, S., \& Slovic, P. (1988). Contingent weighting in judgment and choice. Psychological Review, 95, 371-384.

\section{NOTES}

1. For the sake of simplicity, it is assumed in this article that the costs and the side effects associated with the options in a given choice set are either negligible or are identical so that they should not affect one's choice.

2 . The idea of a roach-shaped chocolate is inspired by Paul Rozin's research on magical thinking.
3. These numbers do not imply that only $68 \%$ minus $46 \%$, or $22 \%$, of the respondents switched their responses between the two questions. Some respondents may have switched their responses in the opposite direction. The difference between $68 \%$ and $46 \%$ indicates the net change.

4. One may argue that the rewards in the point and no-point conditions were not exactly identical. By selecting Task $Y$, subjects in the point condition could potentially choose either the Streisand CD or the Beatles $C D$, but those in the no-point condition could only receive the Streisand $C D$. Then the question is: If students in the point condition ever wanted the Beatles $C D$, why would they bother to take the $60-\mathrm{min}$ Task $Y$ instead of the 50-min Task X?

(Manuscript received July 16, 1998; revision accepted for publication July 27,1999 .) 